\title{
Farm-level Post-harvest Food Losses: the Myth of the Soft Third Option
}

\author{
Martin Greeley
}

\section{Introduction ${ }^{1}$}

Food policy planners concern themselves primarily with two options for increasing food availability. The first of these is more food production and the second is better distribution of the food once it has been produced. Despite the absence of any hard evidence, there is a fairly widespread belief that post-harvest food losses during rice processing are large, and that an important third option in food policy exists viz the prevention of farm-level post-harvest food losses.

Bangladesh produces over $12 \mathrm{mn}$ tons of rice and, according to some commentators, it loses 20 per cent of its production during post-harvest operations [Satake 1978:42; Wimberly 1972:11. Special concern is of ten expressed regarding farm-level drying, storage and milling operations. Traditional processing practices are commonly regarded as unscientific and the source of major food losses. The research emphasis is invariably upon loss-saving innovation and it is rarely recognised that these practices are also the source of approximately 25 per cent of total agricultural employment and represent a vital source of earnings and therefore of food purchasing power [see Greeley 1980, Section 1 ].

This article reports on a study of the post-harvest food system at the farm-level in Bangladesh and evaluates the third option by examining:

- the levels of post-harvest food losses in rice processing operations;

- the implications of technical change in processing methods for food availability.

It is useful first of all to examine the sources and causes of the increased interest in food loss prevention as a third food policy option. We can identify four main causes.

First, production increases due to changes in cropping patterns and the introduction of high yielding varieties have led to increased pressure upon existing postharvest facilities. In our project villages in Modhupur,

Paper presented at the Post-production workshop on food grains, 12-14 December, 1980, Dacca. farmers were harvesting 50 maunds per acre on average in the boro season and this was more than double any of the other rice crops grown there. The higher yields put pressure on threshing, drying, storage and milling facilities. The risk of food loss is further increased because many of the high yielding varieties are thinner husked and therefore more susceptible to pest damage and deterioration in post-harvest operations.

In Bangladesh, the yield increases have come predominantly from a crop harvested in the rainy season which increases the risk of food losses. Attention was, however, first focused on the effect of the HYVs because of the large increase in marketed surplus. In the project villages in Modhupur and Chandina, 27 per cent of the HYV boro crop was marketed, compared to 13 per cent of the aman crop and six per cent of the aus crop (these percentages are on an average household basis). This type of pressure upon handling facilities first occurred in the wheat-growing regions of India in the late $1960 \mathrm{~s}^{2}$; with the spread of irrigation and the change in winter cropping towards wheat, Bangladesh is now starting to face similar problems due to the inadequacy of the marketing infrastructure. These production increases will continue to be an important reason for devoting more resources to the post-harvest handling of grains. But post-harvest constraints beyond the farm-level concern only the marketed surplus, not the totality of the production increase and, as we shall see below, this is an important qualification.

Second, although there is little hard evidence on food loss levels, it is common for very high loss estimates to be discussed [see Food and Nutrition Bulletin, 1979:27]. Figures about food losses tend to be bandied around carelessly without discussion of the loss assessment methods employed. Commonly, no definition of loss is provided and the post-harvest operations included in the estimate are frequently omitted. In effect, they are often meaningless. Lester Brown observed an interesting example where 'according to one calculation, based

2See the excellent study by K. S. Gill [undated] on wheat market behaviour in Haryana and the Punjab from 19681971. 
on local reports, 50 per cent of the grain crop of India was lost to rodents, 15 per cent was lost during milling and processing, 15 per cent was lost to cows, birds and monkeys, 10 per cent was lost to insects and 15 per cent was lost during storage and transit - a grand total of 105 per cent' [Brown 1970:107]. These high loss estimates have provoked the donor agencies and national governments to spend more resources on food loss prevention. Some of these resources have been directed towards farm-level post-harvest problems. In general they have not been used to provide better estimates of food losses but, on the assumption of high food losses, have concentrated upon developing improved technology.

Third, the concern with improving traditional farmlevel and village-level post-harvest practices has been considered synonymous with the introduction of modern technology. It is not surprising therefore that we find that some of the highest food loss estimates are published in journals supported by companies trying to sell rice processing equipment. Examples are not uncommon of inappropriate technological choices being foisted upon national governments by international aid agencies in league with international companies, and it is not trite to observe that there are vested interests in high food loss estimates which promote resource expenditure on improved technology.

Fourth, and this is particularly true in Bangladesh, the levels of food aid have promoted a special interest in the donor community in post-harvest food losses [Comptroller General's Report to Congress, 1976]. This concern is of course legitimate, but again it should be observed that it concerns the marketed surplus or imported grains and is not concerned with farm-level post-harvest operations.

In response to these pressures, national governments, sometimes with the support of the donor community, have begun to encourage post-harvest research. In 1975, the UN General Assembly called for a 50 per cent reduction in post-harvest food losses by 1985 . Many of the donor agencies, but most notably FAO, IDRC, ODA and USAID have supported local research institutes working on farm-level post-harvest problems. Some of these research programmes have been highly innovative though few so far have managed to promote widespread changes in post-harvest practices. In Bangladesh, interest in post-harvest problems is constantly increasing. So far, policy makers in Dacca have only heard the high loss estimates. They have had no evidence of verification, nor have they had suggestions for a solution. The emphasis upon development of new technology has so far not been fruitful, even though in the case of rice drying for example, there have been many research programmes. One of the most important reasons for this is that insufficient attention has been paid to the absolute size of food losses or to looking at them as a part of a total farm system, where management decisions regarding post-harvest operations are integrated with crop production and livestock management decisions. Careful attention must also be given to problems of extension and of organising local manufacturing capabilities. In Bangladesh, there has been some very successful development work which has taken account of all these aspects, but frequently the emphasis upon technology is very narrow. We believe that our evidence presented below on the levels of food losses and on the existing pattern of technical change suggests that technology development which is primarily concerned with loss prevention will not be successful. Food losses in traditional post-harvest operations are very low and technical change is occurring to reduce processing costs, not to prevent food losses.

\section{Food Losses in Farm-level Post-harvest Operations}

The results presented here arise from two years field research in four villages of Modhupur thana, Tangail and four villages of Chandina thana, Comilla. The villages were selected to give representation to all the major rice cropping patterns in Bangladesh. In Modhupur, transplanted crops were grown in the aman, boro, and aus seasons; in Comilla, a deepwater aman crop was grown in single stands or mixed with broadcast aus and some transplanted aus and aman was also grown. Loss estimation work started with the aman season harvest of December 1978 and continued through the following boro, aus and aman seasons of 1979 and was completed with the boro and aus seasons of 1980. Loss assessment studies were conducted for the cutting, field stacking, transportation, threshing, drying, storage and milling operations.

Before presenting loss estimates we must first discuss the definition and measurement of loss. Elsewhere [Greeley and Rahman 1980:3] we have described five main types of food loss: complete physical loss, reduced milling quality, poor consumer observable quality characteristics, nutritive deterioration and development of toxins. A sixth cause of loss in the case of seed grain is reduction in germinability. It is difficult to incorporate these different ty pes of loss into a single index of food loss. Certainly, if we were able to ascribe economic values, a single index would be possible but, measuring the price effect of nutritive deterioration for example, is not really possible because the loss is not necessarily reflected in the selling price of the food grain. Similarly, consumer observable quality characteristics are essentially subjective estimates and vary from region to region. Perhaps because of these difficulties there is 
a general consensus that the major emphasis in loss assessment studies should be upon physical loss.

Physical loss has two components. First, physical loss due to shedding or to grain remaining unthreshed, physical discard of grain which has deteriorated and physical loss due to insects and rodents, mainly in storage. Second, reduced milling quality which is measured as a reduction in the physical yield of polished rice per unit of paddy and by the percentage of brokens in the polished rice. These losses are measured at the time of milling but their cause can be any of the earlier operations from cutting onwards. Cutting a premature crop for example will certainly reduce milling output compared to potential yield or drying in a very hot sun can lead to checking and a consequent increase in the percentage of broken grains. The advantage of concentrating upon these two types of physical loss is that they can be given a direct economic value. The estimates presented below refer to physical food loss.

\section{The measurement of losses}

One of the reasons for the almost complete absence of farm-level post-harvest food-loss estimates is the enormous difficulty of accurate measurement. To estimate shedding losses for example requires a measure of potential yield. One approach is to glean the fields after they have been cut, picking up scattered grains from where the grain has been stacked, collecting fallen grains as the crop is transported to the farmyard and collecting any grains remaining on the threshing floor after stacking and threshing are completed. This work is time consuming, labour consuming and, if not done very carefully and with close supervision, of little value. An alternative approach is to cut sample plots under controlled conditions from the farmer's field to obtain a measure of potential yield and to weigh the farmer's grain after threshing to obtain actual yield. The yield difference as a percentage of potential yield is equal to the loss incurred in the cutting to threshing operations. The obvious disadvantage of this method is that is does not distinguish by operation the incidence of loss. In actual field operation, even more fundamental difficulties were faced due to the difficulty in getting accurate measures of potential yield from small plot areas. Surveys on jute production in Bengal, reported first in 1946, demonstrated that the potential yield estimate from a small sample plot (one square foot) was four times greater on average than the potential yield estimate obtained from a plot of 16 square feet [Mahalanobis 1961]. (After two seasons experimentation with the sample yield approach to measuring potential yield, we were forced to reject it as inaccurate.)

Loss estimates are only useful when they are specified by operation and by cause so, whilst it is relatively straightforward to measure milling quality by looking at the out-turn of polished rice, and only slightly more complicated to measure the percentage of brokens in that rice, it is a far more complex exercise to say what the cause of the reduced milling quality was. There are factors operating in cutting, stacking, threshing, parboiling, drying and storage which can affect the milling quality. To identify the precise cause requires examining one operation, for example different threshing methods, and keeping constant the methods followed in other operations. In the laboratory this is easy; under farm-level conditions it is far more difficult; for example, to ensure that the grain threshed today will be at the same temperature or moisture content as the grain threshed tomorrow.

For these sorts of reasons there have been very few attempts to actually measure physical losses. Far more common have been expert guesses. Carefully done, these can be valuable but commonly they are loose and very unspecific estimates. They tend to move in multiples of five between 10 and 50 per cent and because they do not usually provide a definition or the context (which operations are included) they are of little scientific value.

The loss estimates from the project research are presented in Table 1 and the following paragraphs briefly describe the assessment methods. [These are discussed in more detail in Huq and Greeley 1980:8-13 and 22-24.]

\section{Cutting}

Losses due to cutting were obtained by carefully gleaning part of the farmer's field after he had finished cutting. Each estimate was based upon five two square metre areas randomly selected from within the farmer's field. The farmer's field itself was carefully measured using tapes and ropes; the size of plot was 108 square metres. The loss estimate was obtained by standardising the yield of gleaned grain and the farmer's yield at 14 per cent moisture content and then expressing the gleaned grain yield as a percentage of farmer's yield plus gleaned grain yield.

\section{Field stacking and transportation}

These two loss estimates were obtained by collecting all scattered grains. In the case of field stacking this was done by placing a tarpaulin underneath each field stack and collecting scattered grains after the stack was removed. Transportation losses from field to farmyard were obtained by employing three labourers to follow the labourer carrying the stalk paddy (unthreshed grain) by headload or shoulder pole load, and collecting all the fallen grains into baskets. The farmer's yield was obtained separately for each stack and each transportation load, and after standardising 
for moisture content the loss percentage was obtained as in the cutting method described above.

\section{Threshing}

Threshing losses were measured by re-threshing the farmer's straw and finding how much grain had been left unthreshed. There are two other possible causes of loss during threshing that we must discuss before giving the loss assessment method. First, a type of loss that occurs sometimes is trampling of grain into the mud by bullocks or by scattering of the grain during threshing. Both these types of loss, though extremely difficult to measure, were in our estimation negligible. We based this upon the fact that the family farm women generally took a great deal of care in preparing the threshing floor and in sweeping the threshed grains. Physical losses due to muddy threshing floors can almost always be avoided by sloping the floor and compacting the earth, or by drying it with husk, by covering it with bamboo matting or by extending the stacking period and allowing the floor to dry out. One or more of these practices is necessary in the wet season for much of the harvest. Of course there are cases of carelessness, and cases where a muddy threshing floor has had to be used because of time constraints affecting the availability of labour power and bullock power. However, under usual farm management practices these losses are minimal. Second, a possible cause of loss in threshing is reduced milling yield. In threshing, the grain is subject to stress at the time of separation from the straw and this can lead to internal cracking resulting in an increased percentage of brokens. However, comparing laboratory milling results from traditionally threshed and pedal threshed samples, there was no measurable difference in the percentage of broken grains. It seemed reasonable therefore to base our loss estimate upon grain remaining unthreshed. After the farmer had finished his threshing, we took the weight of his straw and randomly selected a percentage of it, five or ten depending upon the total weight of straw. This straw we then completely rethreshed by careful hand stripping of each individual straw. The yield thus obtained was then winnowed in a manner identical to that of the farmers; this was absolutely essential to ensure a uniform comparison, particularly in some varieties harvested early where many green grains were present. After standardising for moisture content, the loss was calculated as described above for cutting.

\section{Storage}

The loss assessment methods for storage are the most complex of all the operations. This is because the estimation of insect losses requires laboratory analysis of samples. Otherwise insect losses are indistinguishable from rodent losses, the other chief source of loss. Since the implications of the two different sorts of loss may be very different for intervention strategies, it was important to identify the specific cause. The methods followed are described in detail in Huq [1980]. In brief, they required careful measurement of all grain movements into and then out of store during the storage period and collection of a sample at each removal to estimate the levels of insect infestation. The weight loss measured by monitoring the movement of grain in and out of store, adjusted for moisture content, gave an estimate of total physical loss and the sample estimate of insect loss from volumetric techniques used in the laboratory was then subtracted from the total loss estimate and the residual was taken as the rodent loss. This method requires that each and every grain is removed from store it is weighed, and therefore involves close farmer cooperation and frequent visits to the store on the farm; the period of storage, whilst averaging between three to four months, sometimes extended over six months.

The aggregate estimates shown in Table 1 are constructed from the seasonal results detailed in the appendix. The results from each season have been weighted according to their contribution to total production. In the case of differences between broadcast and transplanted varieties, the weight has been further broken down to take account of the production of the two different types. In the case of storage, the weighting between raw paddy, parboiled paddy and parboiled rice was based upon a census conducted in 1978 and 1979 in the project villages. In this census, covering 3,094 households in eight villages, the storage pattern of over 17,000 maunds was monitored and the final estimate of total storage loss is based upon the proportion of total production of rice at these different stages of storage. It takes into account grain which is stored both as paddy and as rice but does not include an almost identical quantity of grain marketed directly after harvest where the storage period was only a few days or less.

The operations missing from the Table are farmyard stacking, drying, soaking and parboiling and milling.

\section{Farmyard stacking}

During stacking at the farmyard, measurable scattering loss does not occur because of the care taken in sweeping. As the stack is at the threshing yard any fallen grain will be included with the threshed grain once the threshing floor has been swept. But delays in stacking may also be associated with physical loss due to the reduction in milling yield occurring as a consequence of mould development on the grain and of premature germination. These have been discussed in [Greeley and Rahman 1980, Table 8] and we may note here that, except for grain stacked for more than one week, there was no measurable effect of stacking 
table 1 Measured physical food losses in rice post-production
operations ${ }^{1}$

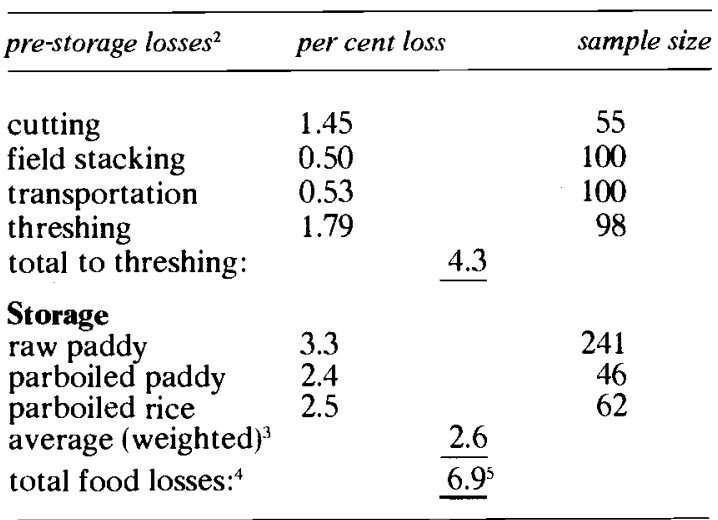

'The estimates for each season and their standard errors are in an appendix.

${ }^{2}$ Loss estimates for broadcast and transplanted crops were obtained in each season and the weights used to calculate these overall loss estimates were based upon the contribution of each type/season to total rice production using 1977-78 production statistics [BBS 1979:167].

${ }^{3}$ The weighting (.19 raw paddy, .39 parboiled paddy, .41 parboiled rice) is based on the storage pattern of over 17,000 maunds of paddy recorded in our village census. The weighting is based on the storage pattern of the major variety cultivated by each of 2,148 households.

${ }^{4}$ Farmyard stacking and drying do not appear in the table because actual physical losses, as opposed to qualitative deterioration, are nearly always close to zero in these two operations under usual farm management practices. The only other possible source of physical loss is reduced milling yield. The effect of poor drying is to increase the percentage of broken grains but otherwise there is no significant effect of traditional post-harvest practices on the overall yield of polished rice.

${ }^{5}$ Strictly speaking losses are not additive in this manner since all the percentages have different bases. In practice the difference is small. On a hundred maunds of paddy a farmer loses 6.9 maunds according to the table and the corrected weight loss is 6.7 .

on milling yield. Quality deterioration including bad odour, discolouration and the development of toxin producing microflora can all result from extended stacking. The food value effects of this deterioration are limited but there are economic losses when grain is sold in poor condition and this strengthens the case for innovations such as the pedal thresher which can reduce the stacking period.

\section{Drying}

In the case of drying two sorts of physical loss can occur. Grain may be scattered whilst on the threshing floor or taken by birds, notably chickens, crows and sparrows. In roadside drying, where the grain is exposed to traffic and in commercial rice mills, where large drying floors make bird control difficult, these sorts of losses are possibly significant. However, in our project villages and as in most of Bangladesh villages, all drying took place under supervision within the bari and on a prepared floor from which the grain was carefully swept up afterwards. Under these circumstances, there were negligible physical losses. As in the case of threshing and stacking, physical losses due to scattering only occur under poor farm management, and small farmers with surplus family labour and producing less than their consumption needs do not usually waste grain for that reason.

The second type of loss in drying is the quality loss caused by increased broken grains in milling as a consequence of drying at too high temperatures in the open sun. This does not affect the physical volume of total rice output and is more likely to occur in the boro and aus harvests when temperatures are higher. Farmers are aware of the risk of cracking and frequently spread the drying operation over several days to allow overnight tempering. Under normal circumstances this keeps losses to a minimum, but when rainy weather prevents a farmer exercising this management control increases in the percentage of broken grains can occur for this reason or because of premature germination. These quality losses, if severe, lead to measurable losses of solids during cooking [Dawlatana 1980].

\section{Soaking and parboiling}

In the case of soaking and parboiling, there is little opportunity for physical losses to occur; in fact the parboiling process, by gelatinising the starch, heals cracks in the rice and actually leads to increased milling yields. Farmers with wet grain and faced by constant rain sometimes keep the paddy in soak for extended periods until the weather is sufficiently bright for them to parboil and dry. Under these circumstances, milling yield can be affected by the grain becoming discoloured and tainted, but as far as physical losses in milling are concerned, we found that over a period of one to seven days soaking, there were no differences in the percentage of polished rice or the percentage of brokens after milling.

\section{Milling}

Losses in milling are discussed in the next section on technical change and it is sufficient to observe here that the highest polished rice yields obtained in our village-level experiments came from dheki processing. 
Therefore, our best estimate of overall physical loss is 6.9 per cent. This is considerably lower than the estimates cited earlier and lower than conventional beliefs of post-harvest scientists about the extent of physical food losses at the farm-level in Bangladesh. Moreover, these losses are spread over five operations and only the storage operation incurred losses greater than two per cent. Therefore the opportunities for effetive economic intervention to reduce food losses at farm-level are restricted to very, very cheap improvements in practices. With the technology options available, there is little hope that these low food losses can be reduced by changes in technique. Bangladesh farmers are traditional but efficient in their postharvest operations. Their traditional methods require careful management and where this is not forthcoming, higher than average food losses do occur. We had examples of farmers suffering storage losses of over 20 per cent and we are sure that similar losses can occur in other operations. But the evidence from this empirical survey strongly denies that these sorts of loss levels occur regularly. It is important to remember also that around 42 per cent of production is harvested in the boro and aus seasons where potentially large wet season losses are only avoided by careful farm management. Moreover, this study provides no evidence on the extent to which market sales of (lower value) wet paddy are made to ease farm management problems. As cropping intensifies and yields increase the risks of losses will also rise as pressure on existing farm-level facilities creates growing management problems. For small farms these problems will rarely be very important but on farms with large marketed surpluses, rain-induced delays are a possible trouble spot and an area where future research is essential.

\section{Technical Change and Food Loss}

With these low loss figures, it is clearly unlikely that the existing pattern of technical change is due to farmer concern with food loss. Table 2 presents loss assessment studies undertaken on two operations where technical change is already occurring in Bangladesh -

table 2

Technical change and food losses

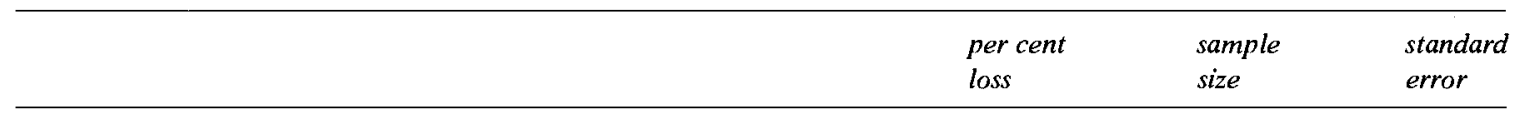

\section{A Threshing}

bullock treading

(broadcast)

$\begin{array}{rrrr} & 2.54 & 40 & 0.29 \\ \text { short straw } & 0.60 & 38 & 0.08 \\ \text { long straw } & 1.45 & 20 & 0.28 \\ \text { short straw } & 1.82 & 10 & 0.39 \\ \text { long straw } & 3.49 & 9 & 0.27\end{array}$

hand beating followed by bullock treading (transplanted)

pedal thresher (transplanted) ${ }^{1}$

per cent

milling yield

per cent

broken grains

sample size

\section{B Husking and polishing}

dheki

72.02

(0.46)

Engleberg-type huller rice mill

69.94

$(0.33)$

28.28

(4.50)

71.87

30.54

(4.52)

laboratory model modern milling

$(0.28)$

8.89

(1.91)

20

20

20

'We only came across one case of a broadcast crop being pedal threshed and the measured loss was 7.3 per cent. In aus 1980 in our four villages in Comilla, 100 per cent of the broadcast crop was bullock threshed and practically 100 per cent of the transplanted crop was pedal threshed.

${ }^{2}$ Figures in brackets are standard errors. 
threshing and milling. What is surprising from these empirical studies is the recognition that food losses actually increase with changes in technique.

\section{Threshing}

The introduction of pedal threshers has been going on for more than 20 years in Bangladesh. They have been spreading very slowly and outside Comilla district, are not particularly widely used as yet. However, there is evidence of an increase in the rate of diffusion, particularly in areas where short, stiff-strawed varieties are grown.

In Table 2, we have broken down the threshing loss estimates according to threshing method. The lowest losses $(0.6$ per cent $)$ are incurred when hand beating followed by bullock treading methods are used for short-strawed varieties. The highest losses (3.49 per cent) are incurred when pedal threshers are used for long-st rawed varieties. Compared to hand beating and bullock treading, the pedal thresher always suffers more losses; in the case of short-strawed varieties three times as many losses and in the case of longstrawed varieties, more than twice as many losses. A comparison with bullock treading of the broadcast crop is not really applicable because the pedal thresher is not suited to the broadcast crop and the one case we observed of it being used for a broadcast aman crop, there was a loss of over seven per cent.

Farmers obviously do not use the pedal thresher to avoid food losses. The main reason is to reduce the time required for the threshing operation. The calculation of the contribution of pedal threshing to reduced labour time is difficult because the traditional methods followed also have significant differences in their labour requirements. Further, the labour and bullock requirements depend upon the variety and the straw length. The average time per maund for pedal threshing was 0.76 man hours in the aus season and 1.09 in the aman season. For traditional threshing methods, the time per maund varied between 0.83 and 4.13 man hours. Bullock threshing of a low yielding broadcast crop gave the 0.83 estimate and 4.13 man hours was the average time taken for hand beating and bullock threshing a high yielding variety in the boro season. It seems therefore that there are opportunities for very significant labour savings if the farmer selects carefully which crops he chooses to pedal thresh. Certainly, on transplanted HYV crops in Comilla, farmers are prepared to pay one seer per maund of paddy for a machine and operator. It is important to note as well that the labour productivity in pedal threshing does depend a great deal upon the operator's skill and upon the number of labourers. Ideally, to maximise output, four labourers - two feeding and two pedalling and threshing-are required.
Farm-level threshing is often constrained by the absence of a dry threshing floor, the non-availability of bullocks, particularly in the wet season when they are preparing the fields for the next crop, and sometimes a shortage of human labour. As these pressures increase with increases in output, the use of pedal threshers is spreading and there are now manufacturers in several parts of the country. The pattern in Comilla may well be replicated elsewhere and therefore we may expect to find small manufacturing units right down to thana level. Finally, a further advantage of the pedal thresher is that it allows the farmer to thresh his grain even when it is raining because the machine can be used inside a room and frequently is. When grain is harvested wet, as in the boro and aus, most of the quality deterioration attributable to rain-induced delays occurs during the stacking period, and with the spread of pedal threshers this stacking period can be reduced or even eliminated.

\section{Milling}

The figures in Table 2 on milling yields compare the dheki with the Engleberg-type rice huller and a laboratory mill which had a Satake rubber roll husker and a Gariboldi truncated stone cone polisher. The laboratory mill gives milling yields which are approximately comparable with those one might obtain using modern milling equipment. To obtain comparable milling results a maund of paddy was divided equally between the dheki and the mill for de-husking and polishing (with a sample kept for laboratory milling) so that differences due to variety and pre-milling processing were eliminated. The results show that the substitution of the rice mill for the dheki is reducing food availability by two per cent and there is also a two per cent increase in the percentage of brokens. The dheki provides a very similar performance to modern rice milling equipment with respect to the percentage of polished rice but suffers 20 per cent more broken grains than modern equipment.

As far as village-level milling is concerned, the relevant comparison is the dheki with the Engleberg-type huller mill, and here it is very clear that as with threshing, the change in technique has reduced food availability by increasing losses during processing. Despite this, the enormous increase in labour productivity (an increase by a factor of 86 ) and the relatively low capital costs of rice mill investment, especially since the spread of electricity, means that the costs of processing are considerably lower in the rice mill than in the dheki. Farmers and traders faced with the prospect of paying wage labour or using the rice mill will clearly prefer the rice mill. In the case of farmers who use family farm labour for de-husking and polishing, the advantages of shifting to the mill are not so clear when female family farm labour is available. For these farmers the real costs of transportation and of milling 
are an additional resource expenditure whereas the opportunity cost of family farm labour, at least as far as the male head is concerned, may be very low indeed. As has been shown elsewhere, ${ }^{3}$ most of the grain going to the rice mill would otherwise have been processed by wage labour women, not family farm women, and in considering the technical change, this employment cost must be given careful consideration. With the inevitability of the continued spread of the rice mills, the employment displacement effect for wage labour women is the most serious consequence of the change in technique.

\section{Implications for Future Post-harvest Research}

Two main results have been established so far:

- physical food losses in farm-level post-harvest operations are below seven per cent;

-the two changes in technique which are now occurring increase food losses.

Two main conclusions follow. First, only in exceptional cases where circumstances cause losses larger than the average figures presented here is there any possibility of changes in technique to prevent food losses; the soft third option does not exist. Second, in the absence of high food losses, the motive force behind changes in technique is opportunities to reduce processing costs. Since most post-harvest operations are very labour intensive - the average value of farmowned capital equipment for processing work is below Tk 100-profitable changes in technique are almost always going to be labour displacing. Innovation in post-harvest operations cannot increase output if there are no losses; therefore, unlike innovation in production which commonly increases demand for labour (eg irrigation and fertilizers) profitable changes in postharvest techniques will be cost-reducing, not output increasing. There are possible exceptions-small-scale driers, for example, could increase labour demand but at existing loss levels are not economically viable.

With total losses averaging below seven per cent, only highly selective loss-saving innovation is possible and the next three sections-concerned respectively with cutting to threshing, wet season practices and milling operations-discuss what policy implications may follow from the existing pattern of technical change.

\section{Cutting to threshing}

Average total losses in these four operations was 4.3 per cent. The seasonal and varietal breakdown of this loss estimate (see Appendix) shows that broadcast and

${ }^{3}$ The economics of technical change in milling are discussed in Shah Noor [1980]. long-strawed varieties are more prone to losses, notably in cutting and threshing. No obvious research or policy implications follow from this result except that it pinpoints the importance of varietal characteristics in determining losses. New varieties that are prone to shattering or conversely extremely difficult to thresh will lead to increases in post-harvest losses. Farmer response to these varietal characteristics can help reduce direct losses but may result in increased indirect losses. For example, a farmer who harvests a shatteringprone variety early may suffer either reduced milling yield or increased drying problems, respectively because of the lower panicle weight and higher moisture content. It is necessary therefore that varietal research and selection procedures include evaluation of post-harvest management as well as yield, drought tolerance, disease resistance etc; shattering and premature germination are of particular relevance, though husk thickness affecting threshing induced milling losses (and also affecting insect losses in storage) is also important.

The only change in technique which is occurring in these operations is the introduction of the pedal thresher. There have been some attempts to manufacture locally powered threshers but these have so far not taken off. The initial promotion of the pedal thresher was largely due to the activities of the Comilla Karkhana, and the gradually increasing use of the thresher now is due to the expansion of acreage under short-strawed high yielding varieties where both losses and labour hours in pedal threshing are minimised. The labour saving is particularly important where there is a short turn-around period between the harvest of the boro crop and the transplanting of the next crop. As we have discussed, the problems of delayed stacking are the chief wet season problem and the rational response is to reduce wet season delays in threshing; pedal threshers which are relatively cheap (Tk 850-1100) and relatively easy to manufacture locally (except for bearings) are able to reduce threshing delays and, because they are very portable, can be used on a customer hire basis. They are a classic example of an intermediate technology, and the plans for expansion in manufacturing capacity during the second Five Year Plan is indicative of their success.

\section{Wet season practices}

Our empirical results on wet season practices have been discussed in detail in an earlier paper [ see Greeley and Rahman 1980]. They are illustrated briefly by the following:

1. Farmers reported a problem of drying raw paddy in only five out of 683 plots.

2. On 28 per cent of these plots farmers suffered delays in threshing due to continuous rain or a muddy threshing floor. 
3. The losses incurred as a consequence of wet season problems were restricted to increases in the percentage of broken grains, and neither physical discard nor reductions in physical milling yield were sufficiently important economically to justify crop driers.

There is a conventional wisdom that wet season losses must be high, and yet in Comilla we frequently found farmers transporting their harvest home by dragging it through the water. Are these poor and highly riskaverse farmers oblivious to losses or is the truth that they know the risks of losses from poor drying are lower in monetary terms than the cost of labour? For the majority of farmers handling relatively small quantities of grain, wet season losses can be avoided by careful farm management. The additional material and labour costs of constructing and operating a small farm drier-where, unlike the pedal thresher, there are no labour savings and only restricted opportunities for customer hire-do not form an attractive investment at the low levels of losses being incurred.

It is important to recognise, though, that the results reported here relate only to farm-level losses, and it is very often the case that larger farmers with a marketed surplus sell wet paddy, sometimes because they need the cash but often because they cannot be sure they will be able to dry their paddy. This minority of farmers with larger investment resources, better risk bearing capacity and facing higher risks of losses are more plausible targets for drier development programmes. The risks of ownership are still large because of the irregularity and uncertainty of demand for the drier facilities. Both for family farm production and for customer hire, these limitations will certainly restrict demand substantially and quite possibly curtail it almost completely.

The location of driers at market centres, perhaps attached to rice mills, is the most likely hope for widespread adoption, particularly in mills which also parboil paddy. However, the economics of operation are still dependent upon a sufficient supply of wet paddy and of paddy that is not already deteriorated. This means that widespread use of driers will be dependent upon the development of the infrastructure (roads and vehicles) to allow farmers to bring grain into market centres quickly when it is wet.

\section{Rice milling}

The two per cent loss noted above has not retarded the growth in number of rice mills which has expanded from 3,583 in 1961 to 7,317 in $1980 .{ }^{4}$ The most important

${ }^{4}$ Figures for 1961 are from Tickner [1974] and 1980 figures are from the Ministry of Food. effect of this technology change however, is in the employment displacement of waged women. In a year long survey of these households, we found that in one region women contributed 23 per cent of household earnings of which nearly half came from post-harvest earnings. The loss of employment opportunities in post-harvest processing therefore presents a serious threat to the livelihood of these families. As we have argued elsewhere [Saleha and Greeley 1979], the particular status of women in the wage labour market and the conditions under which they participate affords an opportunity to provide benefits directly to the poorest by concentrating programmes on wage labour women. Zoning, licensing or other restrictions on rice mill growth are impracticable as there are no effective means available for regulation. Indeed a possible outcome of restricting huller mills would be the growth of a more modern rice milling industry operating inappropriate imported technology with subsidised credit, little labour demand and uncertain profitability. A far better approach is to try and improve the milling performance of small rice mills and to provide organisational and credit resources for wage labour women's cooperatives to make group investments in income generating activities.

\section{References}

Brown, Lester, 1970, Seeds of Change, Pall Mall, London

Comptroller General, 1976, report to Congress [10-76-65] 'Hungry nations need to reduce food losses caused by storage, spillage and spoilage'

Dawlatana, Mamtaz, 1980, 'Effect of milling and \% brokens on cooking loss of rice in Bangladesh'; paper presented at the Post-production workshop on food grains, BCSIR, Dacca, 12-14 December

Food and Nutrition Bulletin, 1979, 'Symposium on postharvest technology and world hunger-Kyoto, Japan', vol 1 no 3 pp 27-28

Gill, K. S., (undated), 'Wheat market behaviour: emerging problems of wheat marketing in Punjab and Haryana postharvest period', Department of Economics and Sociology, Punjab Agricultural University, Ludhiana, India

Greeley, Martin, 1980, Rural technology, rural institutions and the rural poorest', Discussion Paper 154, IDS, Sussex

Greeley, Martin and Siddiqur Rahman, 1980, 'Wet season post-harvest food losses'; paper presented at the Postproduction workshop on food grains, BCSIR, Dacca, 12-14 December

Huq, A. K. Fazlul, 1980, Rice in Bangladesh: estimation of food losses at farm-level storage'; paper presented at the Post-production workshop on food grains, BCSIR, Dacca, 12-14 December 
Huq, A. K. Fazlul and Martin Greeley, 1980, 'Rice in Bangladesh: an empirical analysis of farm-level food losses in five post-production operations'; paper presented at the Regional grains post-harvest workshop, 29-31 January, Kuala Lumpur, Malaysia.

Mahalanobis, P. C., 1961, 'Experiments in statistical sampling in the Indian Statistical Institute', Asia Publishing House, Bombay, Statistical Publishing Society, Calcutta

Saleha Begum and Martin Greeley, 1979 Rural women and the rural labour force in Bangladesh: an empirical analysis', Bangladesh Journal of Agricultural Economics, vol 2 no 2
Satake, Robert S., 1978, 'Status of the rice milling sector', Agricultural Mechanisation in Asia, vol 9 no 2

Shah Noor, Malik Md., 1980, 'Socio economics of rice milling'; paper presented at the Post-production workshop on food grains, BCSIR, Dacca, 12-14 December

Tickner, Vincent, 1974, 'The rice processing and drying sector and government's procurements and distribution policies in Bangladesh', unpublished paper, Dacca, 9 July

Wimberly, James, 1972, 'Review of storage and processing of rice in Asia', paper no 72-01, Agricultural Engineering Department, IRRI

Appendix

Post-production operations: physical food loss

\begin{tabular}{|c|c|c|c|c|c|c|c|c|c|}
\hline \multirow[b]{3}{*}{ pre-storage losses } & \multicolumn{6}{|c|}{$A M A N$} & \multicolumn{3}{|c|}{$A U S / B O R O$} \\
\hline & & \multicolumn{3}{|c|}{ broadcast } & \multicolumn{2}{|c|}{ transplanted } & \multirow[b]{2}{*}{$\begin{array}{l}\% \\
\text { loss }\end{array}$} & \multirow[b]{2}{*}{$\begin{array}{l}\text { sample } \\
\text { size }\end{array}$} & \multirow[b]{2}{*}{$\begin{array}{l}\text { standard } \\
\text { error }\end{array}$} \\
\hline & $\begin{array}{l}\% \\
\text { loss }\end{array}$ & $\begin{array}{l}\text { sample } \\
\text { size }\end{array}$ & $\begin{array}{l}\text { standard } \\
\text { error }\end{array}$ & $\begin{array}{l}\% \\
\text { loss }\end{array}$ & $\begin{array}{l}\text { sample } \\
\text { size }\end{array}$ & $\begin{array}{l}\text { standard } \\
\text { error }\end{array}$ & & & \\
\hline cutting & 2.98 & 17 & 0.71 & 2.06 & 18 & 0.35 & 0.34 & 20 & .08 \\
\hline field stacking & na & na & na & 0.53 & 50 & .04 & 0.46 & 50 & .03 \\
\hline transportation & na & na & na & 0.67 & 50 & .03 & 0.34 & 50 & .02 \\
\hline \multirow[t]{2}{*}{ threshing } & 1.44 & 10 & 0.23 & 1.45 & 20 & 0.28 & $0.60^{1}$ & 38 & .08 \\
\hline & & & & & & & $3.64^{1}$ & 20 & 0.42 \\
\hline & \multicolumn{3}{|c|}{$A M A N$} & & \multicolumn{2}{|c|}{ AUS } & & \multicolumn{2}{|c|}{$B O R O$} \\
\hline storage losses & $\begin{array}{l}\% \\
\text { loss }\end{array}$ & $\begin{array}{l}\text { sample } \\
\text { size }\end{array}$ & $\begin{array}{l}\text { standard } \\
\text { error }\end{array}$ & $\begin{array}{l}\% \\
\text { loss }\end{array}$ & $\begin{array}{l}\text { sample } \\
\text { size }\end{array}$ & $\begin{array}{l}\text { standard } \\
\text { error }\end{array}$ & $\begin{array}{l}\% \\
\text { loss }\end{array}$ & $\begin{array}{l}\text { sample } \\
\text { size }\end{array}$ & $\begin{array}{l}\text { standard } \\
\text { error }\end{array}$ \\
\hline raw paddy & 3.3 & 173 & 0.20 & 3.2 & 40 & 0.39 & 3.5 & 28 & 0.71 \\
\hline paddy parboiled & 2.75 & 18 & 0.80 & 1.9 & 12 & 0.43 & 2.17 & 16 & 0.54 \\
\hline rice parboiled & 2 & 55 & 0.17 & 3.1 & 7 & 0.66 & - & - & - \\
\hline
\end{tabular}

${ }^{10.60}$ per cent for a transplanted crop and 3.64 per cent for a broadcast crop. 